\title{
A Representação Transpõe Freud da Neurologia para a Psicologia ${ }^{1}$
}

\author{
Jaqueline Cristina Rossi ${ }^{2}$ \\ Universidade Federal de São Carlos
}

\begin{abstract}
RESUMO - Neste artigo, demonstraremos que para Freud fornecer uma explicação clinicamente eficaz para a histeria, ele progride da neurologia para a psicologia. A chave que lhe permitirá esta transposição é o conceito de representação em Afasias... porque a representação, neste texto, é uma metáfora psicológica substitutiva de processos fisiológicos complexos, isto é, o fenômeno representacional psíquico revela-se uma função dos processos neurológicos que o constituem.
\end{abstract}

Palavras-chave: Freud; neurologia; psicologia; histeria; representação.

\section{Representation Transposes Freud from Neurology to Psychology}

\begin{abstract}
In this paper, we will demonstrate that in order to Freud give an efficient clinic explanation for hysteria, he progresses from neurology to psychology. The key that will allow him this transposition is the concept of representation in Aphasia... because representation in this text is a psychological metaphor substitutive of complex physiological processes, $\mathrm{i}$. e., the psychic representational phenomenon appears as a function of the neurological processes which constitute it.
\end{abstract}

Key words: Freud; neurology; psychology; hysteria; representation.

De grande interesse para nosso estudo é o verbete Histeria, publicado no Dicionário de Villaret (citado por Freud, 1981b) e atribuído a Freud por razões de autenticidade - observada de sua correspondência com Fliess (Freud, 1986). Já nesta época, Freud anunciara a necessidade de se chegar a uma "fórmula fisiopatológica" para a histeria. Ele sustentava ainda que uma fórmula que fizesse justiça aos fenômenos histéricos não deveria apoiar-se em uma localização anatômica, mas sim em modificações fisiológicas reais do sistema nervoso. No artigo Algumas considerações para um estudo comparativo das paralisias orgânicas e histéricas (Freud, 1981a) essa fórmula começa a se definir, e vai ser expressa como "lesão de uma representação". O intrigante, porém, é que embora Freud defina essa fórmula efetivamente no campo da psicologia, uma leitura de Afasias... (Freud, 1953) mostra que o fenômeno representacional psíquico é derivável do funcionamento do sistema nervoso - que é algo da ordem de um processo eminentemente cortical. Isso quer dizer que Freud substitui processos fisiológicos complexos por uma metáfora psicológica (cuja formação pressupõe a comparação prévia a processos fisiológicos), que só se revela à luz de reflexões sobre o seu conceito de representação tal como formulado originalmente em Afasias...

Examinaremos, neste artigo, o modo pelo qual Freud configura a sua fórmula para a histeria. Com essa finalidade apresentaremos, em primeiro lugar, a formulação do conceito de representação em Afasias... Depois, as questões relativas ao mecanismo da histeria e à sua fórmula patológica. $\mathrm{O}$

1 Artigo derivado de uma Dissertação de Mestrado defendida no Programa de Pós-graduação em Filosofia e Metodologia das Ciências da UFSCar.

2 Endereço: Rua Papa Pio XII, 145, Itapira, SP, Brasil 13974-150. E-mail: jaquerossi@hotmail.com objetivo é mostrar que Freud progride da neurologia para a psicologia por meio do seu conceito de representação em Afasias... - a fim de fornecer uma explicação clinicamente eficaz para a histeria. Pois, em Afasias..., o fenômeno representacional psíquico revela-se uma função dos processos neurológicos que o constituem, isto é, a representação é a metáfora pela qual Freud transfere para o contexto da psicologia o significado de processos fisiológicos complexos, conforme demonstraremos neste estudo.

\section{A Progressão de Freud da Neurologia para a Psicologia: Afasias...}

A necessidade de se chegar a uma "fórmula fisiopatológica para a histeria" fora anunciada por Freud desde seu verbete Histeria (Freud, 1981b), mas para que isso fosse possível foi necessário que ele antes reconfigurasse o "espaço" no qual as funções cerebrais eram localizadas. E é sob o ponto de vista daquilo que Forrester (1980) define esse "espaço" que orientaremos nossa leitura de Afasias... (Freud, 1953). Trata-se de mostrar que Afasias... possibilitou a Freud uma psicologia de representações independentes da estrutura do sistema nervoso. Ao demonstrar que mesmo onde há uma lesão, a afasia devia ser compreendida independentemente da sua localização, Freud preparou o caminho para definir a histeria como a "lesão de uma representação".

No final do século XIX, a teoria das localizações cerebrais e a doutrina da associação de idéias destacavam-se como os dois mais importantes temas de discussão. Os estudos sobre as afasias entre 1861 e 1890 figuravam como o melhor ataque ao problema da localização de funções cerebrais. Uma vez que a identidade entre a anatomia e a função podia se expressar numa teoria da função lingüística, que era, ela própria, parasita da doutrina da associação de idéias, o passo lógico seguinte foi o diagrama. O diagrama representava a 
relação espacial dos centros anatômicos com as relações da função a ele superpostas. Foi dessa maneira que surgiu a localização de um centro para as palavras no cérebro. Mas, antes de avançarmos em nossas investigações, é preciso dizer que como nosso escopo não é reconstruir a história das disputas teóricas em torno das afasias como um fim em si - mas apenas na medida em que essa discussão revelase útil para a compreensão da escolha seletiva de certos pontos de vista que configuram o conceito freudiano de representação - as informações que forneceremos destas teorias serão extraídas das afirmações do próprio Freud e de seus pesquisadores.

Um dos primeiros ataques aos criadores de diagramas, como Head (1926) os cunhou, veio do trabalho do neurologista inglês, John Hughlings Jackson. Forrester (1980) afirma que Jackson queria interromper a "flutuação" entre termos psicológicos e fisiológicos que julgava presente na teoria das afasias e da neurologia em geral, e então, ele fez uma pergunta que o distanciou surpreendentemente de seus contemporâneos: por que esta forma de expressão de preferência a qualquer outra? É exatamente esta distinção que Freud leva da teoria da afasia para a da histeria, sob a oposição entre sintoma e fala. De acordo com Forrester, Jackson postulou que os afásicos sofriam uma lesão em um dado momento, um ataque análogo ao da epilepsia, e "arranjos nervosos" que estavam para ser descarregados, que inervavam a série de nervos motores, eram, desse modo, "pegos no ato" e passavam a reter um alto nível de energia, que não era descarregada em um circuito. Esse circuito permanecia fechado, mas permanentemente ativado. Os outros elementos nervosos revertiam, sob o impacto da lesão, a uma função de ordem inferior. Por fim os arranjos eram fixados no momento do ataque. Assim, as formas de expressão iterativas do afásico correspondiam ao que ele estava para falar no instante do ataque. Portanto, nessa teoria, a dissolução do sistema nervoso, como conseqüência de uma lesão ou de um distúrbio funcional, implicava uma regressão a um estado mais altamente organizado. Porém, um alto nível de organização era a marca de um nível mais baixo de sofisticação do funcionamento nervoso. Desse modo, a consciência correspondia a menos estruturada das relações entre os arranjos nervosos, enquanto que o funcionamento automático envolvia atividades altamente estruturadas e inflexíveis do sistema nervoso. É por isso que quando a forma de expressão quase-articulada foi apanhada na catástrofe conseqüente a lesão disruptiva permaneceu como uma unidade altamente organizada, "presa", dentro do então automático funcionamento do sistema. Enfim, a noção de organização confundiu-se com o conceito de níveis do sistema nervoso: a dissolução trouxe o sistema nervoso de volta a níveis de organização mais antigos e primitivos, possivelmente, aos níveis originais da fala, onde a linguagem já estava "pronta".

Do ponto de vista de Forrester (1980), a despeito dos criadores de diagramas que conservavam um conceito estritamente atomista e nominalista da linguagem, a noção de Jackson era bem mais sofisticada. Para este, as unidades básicas da linguagem eram as sentenças, e não as palavras. E uma sentença possuía sentido na medida em que os elementos que a constituíam fossem sujeitos à substituição.
Quer dizer: uma forma de expressão afásica poderia parecer possuir sentido, mas esse sentido lhe era inerente apenas quando foi proferida originalmente. Quando a formação dinâmica da sentença deixou de existir, em conseqüência da lesão, a frase que já estava "pronta" não podia servir para outras ocasiões, porque não tinha mais sentido.

Freud transpõe da teoria da afasia para a histeria a noção de que a aparente falta de sentido de um sintoma pode ser esclarecida colocando-o no contexto traumático passado, naquele em que ele possuía significação. Mas, em contraste com a expressão iterativa do afásico, o sintoma histérico necessita de uma operação adicional a fim de restabelecer seu significado: a tradução para a frase verbal da qual é expressão iterativa. E isso tem que ser feito antes de colocar o sintoma em seu contexto passado apropriado, se bem que na prática psicanalítica de Freud, os dois procedimentos não sejam separados.

Forrester (1980) assinala que, para Jackson, as palavras só tinham sentido quando formavam parte de um sistema simbólico que representava uma série de estados interiores ordenados e internamente dinâmicos. Mas -a seu ver - neste ponto, Jackson se defrontara com um problema: a linguagem perdida pelo afásico era a lembrança dos signos da linguagem ou a capacidade de produzir signos? Segundo este pesquisador, foi Charlton Bastian - sobre cujas idéias Freud também se apóia - quem passou por cima deste problema. Quer fossem neurônios ou palavras, para Bastian, as unidades envolvidas num processo como a rememoração, não precisavam ser localizadas, porque existiam num espaço psicológico indefinido, independente do cérebro.

Essa mudança no caráter do "espaço" também é expressa por Freud em seu artigo sobre as paralisias histéricas (Freud, 1981a). Nesse artigo, Freud argumenta que a lesão das paralisias histéricas tem que ser completamente independente da anatomia do sistema nervoso. Mais importante, porém, é que conclui seu argumento afirmando que na histeria é uma representação que sofre uma lesão. Por isso a construção do "espaço fisiológico", no qual as estruturas da linguagem são localizadas, constitui-se em um dos principais fundamentos da teoria da histeria de Freud. O caráter fisiológico desse "espaço" pode ser vislumbrado nas categorias básicas do Projeto de uma psicologia de 1895. É que ali a unidade da "mente" é o neurônio, de modo que uma identidade virtual entre neurônio e representação recupera a tópica metafórica essencial da anatomia desse espaço. O que Freud pretende deixar claro é que separar o aspecto psicológico do anatômico não significa separar o aspecto psicológico do neurológico. Ao contrário. Ele afirma que seu esquema psicológico é um esquema derivado de processos neurológicos. Por quê? Porque as associações que formam uma representação são possíveis apenas na medida em que ocorram num registro neurológico, que no Projeto..., são encaradas como estabelecidas pelo movimento das quantidades de excitação cortical (Q). Então, o que Freud está recusando não é o neurológico, mas o anatômico definido em termos de localizações elementares.

Garcia-Roza (1991) afirma que a antiga teoria da localização - da qual Meynert foi um dos principais representantes - afirmava uma relação ponto a ponto entre os estímulos 
provenientes do mundo externo e as representações localizadas em pontos determinados do córtex. Essa relação era tão pontual que as representações corresponderiam a uma projeção 1:1 dos elementos da periferia. É que a principal hipótese desta concepção era que as fibras nervosas deveriam permanecer imutáveis com a passagem de excitação, fazendo apenas a ligação entre centro e periferia.

Em Afasias..., Freud é bastante severo com este modelo. $\mathrm{O}$ argumento que utiliza para recusá-lo tem exatamente duas funções:

a) Ao fazer distinção entre uma percepção e sua associação, dispensa o modelo especular da representação de Meynert.

b) Ao mostrar que mesmo no "esquema corporal" há uma significação funcional de uma fibra sempre que ela se conecta a outras fibras, pretende advertir que, ao nos voltarmos para os fenômenos específicos da afasia, devemos aceitar que a linguagem deve ter uma ordem ainda maior de organização e combinação.

O fragmento seguinte, extraído de Afasias..., exibe a metáfora sofisticada com a qual Freud desenvolve essa ultima função de seu argumento contra a teoria de projeção de Meynert:

Podemos somente presumir que os tratos nervosos que atingem o córtex cerebral, após sua passagem por outras massas cinzentas, mantiveram alguma relação com a periferia do corpo, mas não mais refletem uma imagem tópica exata daquele. Eles contêm a periferia do corpo do mesmo modo que (...) um poema contém o alfabeto, isto é, em um arranjo completamente diferente que serve a outros fins. Quando houver múltiplas associações dos elementos individuais, alguns deles podem ser representados várias vezes, enquanto outros podem não o ser (Freud, 1953, p. 52).

Conforme se vê por esse trecho, toda percepção é codificada em um sistema no qual os elementos individuais contam pouco, porque são as "múltiplas associações" que detêm a informação neural, isto é, a associação entre os elementos corticais precede a representação. É claro que esse associacionismo está claramente distanciado da tradição associacionista clássica, porque retira a primazia dos elementos perceptivos, colocando todo o peso na estrutura dos elementos. Desse modo, a representação é derivada da associação entre os elementos corticais, ainda que só possa ser definida efetivamente no campo da psicologia. É que um fenômeno representacional psíquico contém relações corticais muito complexas, assim como um poema contém $\mathrm{o}$ alfabeto.

Além de incluir uma série de críticas distintas, Afasias... apresenta a primeira versão da noção de aparelho que, a partir daí, ganha destaque na obra de Freud. Olhemos mais de perto as consequiências dessas críticas: ao reforçar que a fala é uma função, Freud chega à conclusão de que todas as afasias deviam ser desordens de associação. Com isso, pretendia limitar a importância da lesão na produção dos sintomas que eram observados na clínica. Para ele, uma lesão não poderia eliminar funções distintas, ela apenas limitava o funcionamento geral do aparelho. É que a unidade do aparelho estava sempre presente no seu ponto de vista. A disfunção do aparelho devia-se simplesmente ao fato de que ele era forçado a operar em um nível funcional diferente, ainda que unificado. É aqui que o dinâmico assume precedência sobre o localizável na metapsicologia de Freud. O território da linguagem define um lugar que Freud assume como uma totalidade, como algo que não é divisível em "centros", mas homogêneo e indivisível. E essa área cortical contínua e homogênea é o que lhe faculta conceber um aparelho de linguagem que funciona em termos de processos.

Toda a discussão que Freud trava em Afasias... o leva a reconhecer que a palavra é a unidade funcional da fala; que ela é uma representação complexa, formada por uma multiplicidade de elementos; mas que, entretanto, é uma unidade do ponto de vista psicológico. Trata-se, portanto, de uma crítica à teoria das localizações cerebrais. Se, de um lado, os adeptos desta teoria defendiam que aquilo que se apresenta à introspecção como algo simples (uma idéia, uma palavra, uma sensação), corresponde, no nível neurológico, a algo igualmente simples, de outro, Freud afirma que tal correspondência é diversa: algo psicologicamente simples remete a algo neurologicamente complexo. A referência à palavra como uma unidade funcional também implica a noção de que o substrato neurológico da linguagem não é apenas complexo, mas dinâmico; algo da natureza de um processo. Mas, afinal, em que sentido uma palavra pode ser complexa?

No Capítulo IV de Afasias..., Freud propõe um esquema psicológico da representação-palavra e lista seus componentes usualmente aceitos: a imagem acústica, a cinestésica e a visual da palavra. Porém, longe de ser só isso, a enorme complexidade conferida à palavra só se explica através de sua natureza de processo cortical funcional e dinâmico. De fato, em Afasias..., Freud demonstra detalhadamente que durante as sucessivas fases do processo de aquisição da linguagem, ocorrem processos associativos que se acrescentam, reorganizando-se aos adquiridos anteriormente, isto é, se "sobre-associam". Assim, a cada nova etapa do desenvolvimento da linguagem, formam-se novas conexões que englobam tudo o que já foi alcançado até então. Resulta que cada etapa consiste numa reestruturação global do aparelho de linguagem. Originariamente, o único componente da representação-palavra que não sofre esse processo de sobre-associação é a imagem acústica, já que é a primeira a ser adquirida na seqüência cronológica, é por isso que a imagem sonora é o aspecto central da representação-palavra. Em resumo, se a representação-palavra é uma representação complexa que inclui elementos acústicos, visuais e cinestésicos, então, estes elementos não podem ser dissociados uns dos outros. Além disso, qualquer operação da linguagem, por mais simples que possa ser, implica a intervenção simultânea de funções de mais de um ponto do território da linguagem. Vem daí que o processo que ocorre no aparelho de linguagem é um processo de associação.

A essa classe de associações da representação-palavra vem se associar uma outra: a representação-objeto. Ora, há um só modo de definir a natureza desta última, é compará-la toda a representação-palavra, o comum e o diverso entre ambas. Nesse caso, é preciso examinar algumas das 
idéias de J. S. Mill, porque existem alguns aspectos da representação em Freud que melhor se explicam à luz deste autor.

Ao contrário do pai, James Mill (1974a) - que professava um associacionismo bem ortodoxo, em que os conjuntos de elementos eram concebidos como simples agregados, visto que a natureza elementar dos conjuntos não era alterada pelo fato dos elementos encontrarem-se associados uns aos outros -, Stuart Mill (1974b) formulou uma "química mental", na qual os elementos que se combinam na produção de propriedades eram irredutíveis às suas propriedades elementares. Note-se que a concepção de associação adotada por Freud aproxima-se bastante desta. Pois - como vimos - ele considera que os elementos das representações são os processos neurológicos que as constituem. E se as representações são o material de composição do psíquico, elas devem consistir em complexos que adquiriram propriedades inencontráveis em seus elementos. Mas não é só isso. A verdade é que Freud leva esse raciocínio bem mais longe, indo além do próprio Stuart Mill. Veja-se: se, para este, os elementos possuem propriedade elementares que não se transmitem tais quais ao composto, porém, combinam-se, "quimicamente", no engendramento de novas propriedades, por outro lado, ele não está preocupado - como o neurólogo Freud - em dar conta da transposição do neurológico ao psíquico. Para ele, os elementos das associações são de natureza psíquica; ou melhor, existem psiquicamente, por si sós, como átomos mentais; no que ele diverge do pai é sobre o modo como se constroem as propriedades (isto é, a natureza) dos fatos psíquicos complexos: se por soma ou agregação ou por uma combinação de fato digna deste nome. Já Freud considera que os elementos das representações não têm existência psíquica em si mesmos, mas apenas como integrantes de um complexo que, em última instância, os constituem enquanto elementos, tanto quanto esse mesmo complexo é constituído pelos processos nos quais se dão esses elementos. Isso fica bem claro no caso da representação-palavra: uma letra só é uma letra na medida em que faz parte de uma representação-palavra; fora isso, ela é um traço perceptivo como qualquer outro. De qualquer forma, as idéias de $\mathrm{S}$. Mill agradaram muito a Freud, não podemos esquecer que o próprio termo "psicanálise" é uma metáfora química. Além disso, no que diz respeito à representação-objeto, foram às idéias deste filósofo referentes ao problema da crença na realidade exterior e na dessusbstancialização do conceito de matéria que facultaram a Freud defini-la.

A começar, Freud define a representação-objeto como "outro complexo de associações, composto das mais variadas impressões, visuais, auditivas, táteis, cinestésicas e outras" (Freud, 1953, pp. 77-78). Mas, então, até aí, Freud não lhe atribui uma natureza muito diferente da representação-palavra. Isso, por um lado, autoriza-nos a generalizar algumas conclusões sobre esta para a teoria da representação como um todo, mas, por outro, traz o problema: o que as distingue então? A única diferença apontada por Freud surge na legenda do esquema que apresenta a ambas: " $A$ representação-palavra aparece como um complexo fechado de imagens; a representação-objeto como um complexo aberto" (Freud, 1953, p. 77). Entretanto, o sentido desta distinção só se torna claro quando Freud, de modo explícito, introduz duas citações de S. Mill para caracterizar a representação-objeto:

De acordo com o ensino filosófico, a representação-objeto não contém nada mais [do que aquela série de impressões e as associações entre elas]; a aparência de uma "coisa", cujas "propriedades" são-nos transmitidas por nossos sentidos, origina-se apenas do fato de que, ao enumerar as impressões sensoriais recebidas de um objeto, nós aceitamos a possibilidade de uma longa série de impressões ser acrescentada à cadeia de associações (J. Mill citado por Freud, 1953, p. 78)

E então, ele finalmente conclui explicando a legenda do esquema da representação-palavra: “É por isso que a representação-objeto não nos aparece como fechada - $e$, na verdade, como dificilmente 'fechável' -, enquanto que a representação-palavra nos aparece como fechada, embora capaz de extensão" (Freud, 1953). Essas passagens demonstram que a representação-palavra é uma representação à qual não vêm acrescentar-se novas impressões, provocando a ilusão que, por traz da representação, perfile-se um objeto da realidade. Ela aparece como um puro signo, que adquire secundariamente a sua significação através da associação com a representação-objeto. Repare-se que, quando Freud diz que a representação-palavra é fechada "embora capaz de extensão", refere-se a que os elementos cinestésicos, visuais e acústicos que a compõem podem multiplicar-se indefinidamente (nos casos de ampliação de vocabulário, na aprendizagem de novas línguas, etc.), entretanto a representação-palavra nunca conterá nada além de uma imagem acústica da palavra, de uma imagem cinestésica da fala, de uma imagem visual da leitura e de uma imagem cinestésica da escrita. Inversamente, a representação-objeto é aberta ao surgimento de novas impressões que até então haviam escapado à percepção, embora, apesar disso, não pensemos estar percebendo um novo objeto.

O último aspecto a assinalar sobre estes dois complexos de representações é que a associação entre ambos não ocorre em bloco, mas entre alguns de seus elementos. Essa relação ocorre quando a imagem acústica da representação-palavra se associa com a imagem visual da representação-objeto. É pela via da nomeação, portanto, que se dá a associação entre esses dois complexos. Por isso, a associação entre estes é responsável pela significação. Enfim, ambos os sistemas de representações possuem uma ordem, um "código de combinação" independente da estrutura do sistema nervoso.

\section{Das Afasias para a Histeria: A "Fórmula para a Histeria"}

Desde 1888, no verbete sobre a histeria para o Dicionário de Villaret (Freud, 1981a), ao falar das paralisias histéricas, na seção que lhe fora reservada, e ao fazer um cotejo entre estas e as orgânicas, Freud recusava a tentativa de Charcot de fazer derivar os sintomas histéricos das lesões dinâmicas. As paralisias histéricas eram, assim, substancialmente diversas das paralisias orgânicas. Afastavam-se tanto daquilo que se sabia ou se supunha sobre a estrutura e a função do sistema nervoso, que era necessário postular para sua gênese, um 
mecanismo totalmente diferente daquele das lesões dinâmicas localizadas anatomicamente.

As tentativas de Freud conceber para as paralisias histéricas um mecanismo diferente daquele das paralisias orgânicas conduzem-no aos resultados que obtivera através de seus estudos sobre as afasias em 1891. É que - como vimos na seção anterior - o tratado sobre as afasias servirá de modelo teórico para que a natureza da lesão na paralisia histérica seja explicada.

Logo na abertura do artigo sobre as paralisias histéricas, Freud descreve os dois tipos de paralisias reconhecidas pela clínica: a paralisia perifero-espinhal (ou bulbar) e a paralisia cerebral. Assim, conjetura que a primeira se caracteriza por ser detalhada e intensa: "A periferia está, por assim dizer, projetada ponto por ponto sobre a substância cinzenta da medula. Propus denominar paralisia de projeção à paralisia detaillé perifero-espinal” (Freud, 1981a, p. 198). Enquanto isso, a segunda dá-se em massa, de forma difusa e ampla. Nesse caso, a relação da medula com o córtex ocorre de modo a um elemento cortical poder estar representando numerosos elementos da medula ou, inversamente, um único elemento medular pode representar diversos elementos periféricos:

Por isso, sustento que a reprodução da periferia no córtex já não é uma reprodução fiel ponto por ponto, não é uma projeção genuína; é uma relação mediante fibras, que podemos chamar de representativa, e proponho para a paralisia cerebral o nome de paralisia de representação (Freud, 1981a, p. 199).

Essa última passagem fornece a caracterização de uma paralisia de representação como algo da ordem de um processo global do sistema nervoso. No tratado sobre as afasias de 1891, Freud emprega o termo representação para descrever um modo de funcionamento do sistema nervoso, sem precisar distingui-lo taxativamente daquilo que a psicologia designava como representação. Mais importante, porém, é que, partindo desta caracterização, Freud prenuncia a construção de uma "fórmula para a histeria" que se figura em Paralisias.... "A histeria nunca simula as paralisias perifero-espinhais ou de projeção; as paralisias histéricas compartilham somente dos caracteres das paralisias orgânicas de representação” (Freud, 1981a, p. 199).

Temos aqui o plano geral do mecanismo que determina a paralisia histérica. Como se verá, ela assemelha-se a uma paralisia orgânica de representação, causada pela ocorrência cortical de uma lesão exclusivamente funcional ou dinâmica. Ora, é exatamente isso que Freud denominará "lesão de uma representação” (Simanke, 1999). Mas vamos por partes.

À medida que Freud torna a recapitular seu ensaio sobre as afasias, a comparação entre a paralisia cerebral orgânica e a afasia orgânica segue retomando o argumento da redução do número de fibras aferentes, para distinguir novamente, a paralisia de projeção da paralisia de representação. Dessa distinção decorre a explicação da impossibilidade da paralisia cerebral orgânica ser isolada e delimitável, embora isto seja possível na paralisia histérica. Diz ele:

... a paralisia histérica é, então, de uma delimitação exata e de uma intensidade excessiva; possui essas duas qualidades e nisto reside seu maior contraste com a paralisia cerebral orgânica, na qual, de uma maneira contrastante, estes dois caracteres não estão associados (Freud, 1981a, p. 202).

Não se trata simplesmente de falar da distinção da paralisia orgânica e da histérica; pode-se extrair também dessa afirmação, a independência do sintoma histérico com relação à anatomia nervosa: "Como só pode existir uma única anatomia cerebral que seja verdadeira, e como ela encontra sua expressão nas características clínicas das paralisias cerebrais, evidentemente, é impossível que esta anatomia possa explicar os traços distintivos da paralisia histérica" (Freud, 1981a, p. 205).

Esses trechos demonstram também que a paralisia histérica apenas simula as paralisias orgânicas de representação, o que nos leva a investigar a natureza dessa representação que não tem fundamento anatômico. Em face disso, Freud recorre a uma tese herdada da neuropatologia francesa: "Charcot nos ensinou que, muito freqüentemente, ela [a lesão histérica] é uma lesão cortical, mas puramente dinâmica e funcional" (Freud, 1981a, p. 205). Como não concordasse com essa tese, que é expressão dos esforços de Charcot de localizar as paralisias histéricas, Freud a reinterpreta num rompante:

Eu afirmo, ao contrário, que a lesão das paralisias histéricas deve ser por completo independente da anatomia do sistema nervoso, já que a histeria se comporta em suas paralisias e outras manifestações, como se a anatomia não existisse, ou como se não tivesse nenhuma notícia dela (...), toma os órgãos no sentido vulgar, popular, do nome que levam: a perna é a perna até a inserção da cadeira; o braço é a extremidade superior, tal como é desenhado pelas roupas. Não há razão para reunir paralisia do braço e paralisia do rosto (Freud, 1981a, pp. 206-207).

Essa passagem - além de acentuar a crítica às afirmações de Charcot sobre o papel das lesões dinâmicas - demonstra que são as concepções populares do corpo que direcionam o sintoma histérico. Por aí, fica evidente que a lesão histérica não é de natureza orgânica. Aliás, até agora, ela só fora definida por negativas. Resta explicar no que de fato consiste a "lesão de uma representação". Isso ocorre somente na Sessão IV deste artigo. Vejamo-la:

Tomarei a expressão "lesão funcional e dinâmica” em seu sentido próprio de "alteração de função ou de dinamismo", alteração de uma propriedade funcional. Uma alteração assim seria, por exemplo, uma diminuição da excitabilidade ou de uma qualidade fisiológica que, no estado normal, permanece constante, ou varia dentro de limites determinados (Freud, 1981a, p. 207).

De uma forma geral, é a gênese da metapsicologia freudiana que se observa aqui: trata-se de uma reflexão teórica que forja os conceitos necessários para que os fatos clínicos tornem-se inteligíveis. Mas a questão da excitabilidade introduz o problema da especificidade da lesão histérica. Por isso, afirmar o caráter funcional do distúrbio histérico não basta para explicá-lo de modo eficiente (Simanke, 1999). Como ficava suficientemente comprovado em Afasias..., ele poderia ter uma origem orgânica. Registre-se, então, que 
será esse impasse que terá que ser contornado: "Tentarei mostrar que pode existir uma alteração funcional, sem lesão orgânica concomitante, ao menos, sem lesão grosseira palpável, ainda que através da análise mais cuidadosa” (Freud, 1981a, p. 207).

Nesse sentido, convém destacar que a idéia de uma "alteração funcional sem lesão orgânica" coincide com aquilo que Freud estabeleceu na sua teoria da representação em Afasias (1891). Isso significa ingressar no terreno da psicologia, para o que pede licença nesse momento. É que Freud apresentara o conceito de representação, em 1891, como algo da ordem de um puro funcionamento cortical, sem haver recorrido a qualquer forma de anormalidade orgânica. Todavia, cabe aqui uma distinção: se em Afasias... (Freud, 1953) um distúrbio representacional tem como causa uma lesão material, Paralisias..., ao contrário, descreve um processo que ocorre apenas no plano representacional (Simanke, 1999), que é onde Freud tem que buscar as causas desse processo agora. Então, não é à toa que ele prioriza a explicação psicológica, a ponto de se poder aceitar que são as concepções populares do corpo que direcionam o sintoma histérico: "A lesão da paralisia histérica será, então, uma alteração da concepção \{representação $\}^{3}$ da idéia de braço, por exemplo" (Freud, 1981a, p. 208).

Essa descrição de Freud a propósito da organização psíquica também pode ser encontrada em Charcot. Mas a idéia fundamental que se expressa nesse fragmento, também fundamental para a teoria da histeria, é a de que a representação possui uma intensidade afetiva. E é à intensidade afetiva da representação que se deve a paralisia histérica. Observemos que a teoria breueriana da histeria consiste basicamente no desenvolvimento dessa idéia. Registre-se ainda a continuidade entre essas observações freudianas, embora restritas a um fenômeno particular, no caso as paralisias histéricas, e as teses de Breuer. Freud chega mesmo a, mais de uma vez, fazer referências às idéias que ele e Breuer estavam então elaborando. Aliás, elas apareceriam neste mesmo ano (1893) na Comunicação preliminar. Veja-se uma destas passagens em Paralisias...:

Se a concepção de braço está envolta em uma associação de grande valor afetivo, será inacessível ao livre jogo das outras associações. O braço estará paralisado na proporção da persistência deste valor afetivo, ou da sua diminuição por meios psíquicos apropriados. Temos aqui a solução do problema a que nós [Freud e Breuer] temos buscado, pois, em todos os casos de paralisias histéricas encontramos que o órgão paralisado ou a função abolida estão envoltos em uma associação subconsciente, provista de um grande valor afetivo, e pode-se mostrar que o braço se libera tão logo esse valor afetivo se desvaneça. Portanto, a concepção de braço existe no sustento material, mas não é acessível para as associações e impulsos conscientes, porque toda sua afinidade associativa está, por assim dizer, saturada em uma associação subconsciente com a lembrança do sucedido, do trauma, do ocasionador da paralisia (Freud, 1981a, p. 208-209).

Para começar, os "meios psíquicos apropriados" a que Freud se refere nesse longo fragmento são o próprio método catártico, cuja invenção atribui a Breuer. Desse processo, decorre uma explicação para o mecanismo psíquico da paralisia histérica mais completa que aquela que vimos em 1888. Nesse caso, há uma afinidade associativa entre a concepção (dada pela linguagem) do órgão ou função e o trauma. Essa afinidade é dotada de grande valor afetivo, mas nem por isso é consciente; ao contrário, é inconsciente, afastada das associações. Porque essas associações, na concepção freudiana, são formadas por representações conscientes, de modo que só um conjunto delas é que pode definir para o sujeito seu saber prático sobre o seu próprio corpo. Se, por outro lado, não for possível o percurso entre as representações conscientes sobre o corpo - via linguagem - e uma outra que se vinculou de forma não consciente, em decorrência do trauma, ocorre uma paralisia histérica. Isso nos indica que, a função perturbada é a de nomear certas partes do corpo, isto é, as que se vincularam ao trauma (Gabbi Jr, 1990).

Nos termos dos sistemas de representações palavra/objeto de Afasias..., o que acontece é que uma relação entre a representação da palavra e a associação do objeto é recusada - um mecanismo semelhante ao que Freud chama de afasia assimbólica. Como conseqüência desta recusa, funções inferiores, aprendidas mais cedo, são trazidas à ação. Quer dizer: as palavras encontram seu "local exato material" antes no corpo que nos sons, tornando-se gestos (Forrester, 1980). Repare que isso é semelhante às afirmações de Jackson (1958a, 1958b) relativas às formas de expressão iterativas dos afásicos. É que estas, a seu ver, eram pensamentos imobilizados, repetidos, "já prontos”, fora do controle do afásico. Donde Freud conclui mais tarde que a histeria deve-se a uma incapacidade de transferir as representações (traumáticas) para a consciência verbal, porque essa incapacidade só era adequada ao período em que não se podiam traduzir quaisquer representações na consciência verbal. Tal período corresponde ao de 0 a 4 anos na criança.

Mas, de qualquer forma, no artigo sobre as paralisias histéricas (1981a), Freud define a lesão histérica como sendo produzida pela interrupção associativa entre as representações do eu do histérico ${ }^{4}$ e a concepção ou função do corpo relacionada ao trauma. Essa é a razão da referência constante ao uso de termos que só se explicam no terreno da psicologia:
3 O artigo sobre as paralisias histéricas (Freud, 1981a) é um artigo escrito em francês, no qual Freud emprega o termo "répresentation" para designar "Repräsentation", termo que em Afasias... ele opunha ao conceito de projeção de Meynert, para designar a relação entre a estimulação sensorial periférica e a atividade cortical. Já o termo "conception", neste artigo, é empregado para exprimir a "Vorstellung", ou seja, o conceito psicológico de representação.
4 À medida que a concepção do conflito neurótico como processo que dá origem ao sintoma for-se firmando em Freud, o eu passará a aparecer como instância psíquica que representa o pólo defensivo desse conflito, em oposição ao recalcado, cuja natureza sexual será cada vez mais enfatizada. 
Em resumo (...), a lesão nas paralisias histéricas não consiste em outra coisa que a inacessibilidade à concepção do órgão ou à função para as associações do eu consciente. Esta alteração puramente funcional (...) é causada pela fixação da dita concepção, em uma associação subconsciente, com a recordação do trauma. E, esta concepção não se tornará livre e acessível, até que o valor afetivo do trauma psíquico tenha sido eliminado pela reação motriz adequada ao trauma psíquico (Freud, 1981a, p. 210).

No artigo publicado com Breuer em 1893, Freud expõe ainda melhor esse mecanismo psíquico: a exclusão da associação (com outras representações) ocorre porque a associação inconsciente com a lembrança do trauma carrega a representação em questão com um Affektbetrag (uma quota de afeto) - precisamente, como na história cômica do fiel servente que sempre recusava lavar suas mãos depois de serem tocadas pelo rei. Isso marca uma importante diferença em relação à formulação de Charcot. Aquilo que Charcot percebeu como uma "idéia poderosa" passa a ser concebida por Freud como uma representação carregada de uma quota de afeto.

Enfim, Freud pôde vislumbrar duas coisas dessa longa progressão: por um lado, a convicção de que as neuroses e a histeria tinham que ser explicadas em termos psicológicos, e de outro, um insight sobre a possibilidade de um tratamento psíquico.

\section{Conclusões}

Conclui-se que o esforço de Freud progredir da neurologia para a psicologia the facultou uma explicação para os fenômenos histéricos conforme seu ceticismo a respeito da localização das funções cerebrais o convidou a fazê-lo. A chave que lhe permitiu esta transposição foi a definição do conceito de representação em Afasias... Uma leitura deste texto demonstrou-nos que, de fato, a representação, embora defina-se efetivamente no campo da psicologia, é uma função (em sentido estrito, no que se refere ao ponto de vista funcional) dos processos neurológicos corticais que a constituem; ela é um produto do movimento das quantidades, que estabelece as associações, porém, estas associações não são "atos originários", não são psíquicas, a não ser na medida em que constituem as representações.

Assim, em 1893, quando Freud proclamou a independência da lesão histérica em relação à anatomia do sistema nervoso, ele já a havia obtido dois anos antes para a lesão afásica. $\mathrm{E}$ o fato dele ter conseguido mostrar que mesmo onde havia uma lesão orgânica - como no caso das afasias - a explicação não deveria recorrer apenas à hipótese da localização da lesão, o impeliu a compreender a histeria como a "lesão de uma representação". Quer na afasia, quer na histeria eram os dois sistemas de representações (o de palavra e o de objeto) que sofriam lesões.

\section{Referências}

Gabbi Jr., O. F. (1990). Sobre a concepção da afasia e da histeria: notas sobre a relação entre anatomia e linguagem nos primórdios da teoria freudiana. Em B. Prado Jr. (Org.), Filosofia da psicanálise. (pp. 181-198). São Paulo: Brasiliense.

Garcia-Roza, L. A. (1991). Introdução à metapsicologia freudiana: sobre as afasias; o Projeto de 1895, Volume 1. Rio de Janeiro: Zahar.

Forrester, J. (1980). Language and the origins of psychoanalysis. New York: Columbia University Press.

Freud, S. (1953). On Aphasia. A critical study. New York: International University Press.

Freud, S. (1981a). Algunas consideraciones con miras a un estudio comparativo de las parálisis motrices orgánicas e histéricas . Em J. Strachey (Org.), Sigmund Freud, Obras Completas. Volume 1 (pp. 191-210). Buenos Aires: Amorrortu Editores.

Freud, S. (1981b). Hysterie (1888). Em J. Strachey (Org.), Sigmund Freud, Obras Completas. Volume 1 (pp. 41-65). Buenos Aires: Amorrortu Editores.

Freud, S. (1986). A correspondência completa de Sigmund Freud para Wilhelm Fliess (1887-1904). Rio de Janeiro: Imago editora.

Head, H. (1926). Aphasia and kindred disorders of speech. Cambridge: University Press.

Jackson, H. (1958a). Evolution and dissolution of the nervous system (1884). Em J. Taylor (Org.), Select Writings of John Hughlings Jackson, (pp. 45-118). New York:Basic Books.

Jackson, H. (1958b). On affections of speech from disease of the brain (1878-80). Em J. Taylor (Org.), Selected writings of John Hughlings Jackson (pp. 171-183). London: Staples Press.

Mill, J. S. (1974a). A system of Logic Ratiocinative and Inductive (1843). Em Collected Works of John Stuart Mill. Volume 7. Cambridge:University Press.

Mill, J. S. (1974b). Um exame da filosofia de Sir William Hamilton (1865). São Paulo: Abril Cultural.

Simanke, R. T. (1999). Afeto e representação na histeria. São Carlos: UFSCar/Departamento de Filosofia e Metodologia das Ciências. Notas de aula.
Recebido em 22.07.2005

Primeira decisão editorial em 16.01.2006

Versão final em 11.05.2006

Aceito em 29.03.2007 